\title{
Methods for Measuring Gender Diversity Among College and University Faculty
}

\author{
Stephanie A. Bohon \\ University of Tennessee \\ Nicholas N. Nagle \\ University of Tennessee
}

We demonstrate how techniques that sociologists and geographers developed to study racial segregation of neighborhoods can provide a means to better evaluate gender equity in higher education. We demonstrate how four dimensions of diversity among the professorate can be calculated. We also discuss how administrators armed with these kinds of information can better evaluate how their institution and departments are fairing over time and in relationship to the larger academic labor market. Administrators can also use these methods to develop a base for comparing their institution to peer and aspirational peer institutions.

Keywords: Segregation, Gender Diversity, Higher Education, Evenness, Exposure, Concentration

\section{INTRODUCTION}

Vertical gender segregation - the tendency of men to occupy more prestigious and better paying positions than women (Charles \& Grusky, 2004; Jacobs, 1989; Reskin \& Roos, 1990)-negatively impacts work experiences and renumeration for women. Vertical gender segregation at universities that sort men in the professorate into higher prestige departments than women reduces women's access to resources and connections which, in turn, impacts their ability to earn tenure and promotion (Misra, Kennelly, \& Karides, 1999; Probert, 2005; Weisshaar, 2017). Departments with healthier gender balances attract more diverse pools of graduate students, while those that continue to be male-dominated have gradute student cohorts that are mostly comprised of men, limiting future diversity (Hale \& Regev, 2014; Moss-Racusin et al., 2012). Most university administrators are aware of the problem (see Shaw \& Stanton, 2012), and many universities have implemented programs that attempt to attract more women to their science, technology, engineering, and mathematics (STEM) departments (Xu, 2008) as well as to other fields where women are traditionally underrepresented, like accounting, philosophy, and economics (Bayer \& Rouse 2016).

When departments are not diverse, they often argue that their pools of candidates applying for positions are not diverse (see Shultz, 2018). This may be true, but it may also reflect a lack of commitment to diversity or they may not see problems that limit their ability to attract diverse hires (Bystydzienski et al., 2017). Thus, college and university administrators need to develop a range of 
methods for tracking how their departments are doing over time and relative to the overall field-specific academic labor market in order to determine which departments need extra attention.

College and university gender diversity statistics are typically comprised of the percent of the faculty who are women and men. These data have some value, but basic stastistics mask vertical gender segregation. A university whose faculty are comprised of 50 percent women may have women segregated in women-dominated departments (like Library Sciences) while men dominate the Business School and Engineering departments where positions are better renumerated (Li \& Koedel, 2017). Even when these statistics are reported by field, the information is not much more illuminating. If 16 percent of the Biology faculty are women, is that because the Biology Department has done a poor job of recruiting and retaining women, or is it indicative of the larger labor market from which the department could select new faculty members? It is also difficult to determine from basic percentages if improvements over time reflect real institutional progress - real improvements to the work environment, better recruiting and retention techniques, and stronger leadership - or if they reflect larger, systemic changes such as changes in the stream of women into graduate programs.

We assert that by calculating relatively simple demographic indices of segregation using data that colleges and universities already collect will provide administrators more in-depth information about progress across time, and provide researchers with good benchmarks to create more complex models to compare diversity across institutions and fields. Using algorithms already developed and commonly employed to study neighborhood segregation at the metropolitan level and applying those alogrithms to college and university settings will allow for a greater understanding of gender diversity and change among the professorate. In this paper, we demonstrate methods for examining evenness, exposure, concentraton, and field proportionality using data from the University of Tennessee-Knoxville (UTK). These same techniques can be implemented at other large institutions relatively easily and can be adapted for use in measuring other types of diversity, such as racial inclusion. Our methods in this paper are neither novel nor complex; we argue that the simplicity of the basic measures used make these especially valuable tools for developing and implementing better university diversity metrics.

\section{RESIDENTIAL SEGREGATION AND ITS APPLICATIONS}

Sociologists and geographers have long grappled with understanding the degree to which people of color live apart from whites in segregated neighborhoods and whether neighborhoods are becoming more integrated or separated over time (e.g., Massey, 1985; Iceland, Weinberg, \& Steinmetz, 2002; Crowder \& Krysan, 2016). Thus, social scientists developed (and continue to develop) myriad methods for measuring neighborhood diversity. In fact, there are so many methods that thirty years ago Massey and Denton (1988) examined commonly used measures of residential segregation to conclude that twenty-five indices represented five distinct dimensions of segregation.

Some of these dimensions are useful ways to consider diversity among the professorate. If we conceive of the university as a city and departments as neighborhoods, we can apply some of the same techniques. In this paper, we examine evenness (the degree to which women are proportionally spread across departments), two measures of exposure (the degree to which women are likely to encounter colleagues who are men), concentration (the degree to which women are positioned in ways that gain them access to power), and field proportationality (the degree to which the hiring of women in a department reflects the availability of women in the labor pool).

To better understand how residential segregation measures can be applied to studying gender diversity among the professorate, consider how one measure of evenness - the index of dissimiliarity - is used in urban studies. The index of dissimiliarity measures the extent to which the racial composition of neighborhoods reflects the racial composition of a city as a whole. For example, if a city is 80 percent white and 20 percent people of color, then it is "even" if every neighborhood that makes up that city is also 80 percent white and 20 percent people of color.

One of the advantages of the index of dissimilarity is that it yields a number that is easy to interpret. An index score of .75 means that 75 percent of the population would have to be relocated (white residents 
to more black neighborhoods or black residents to more white neigborhoods) in order to achieve evenness. Overall, numbers closer to 1 indicate that neighborhoods tend to be segregated by race; numbers closer to 0 indicate that neighborhoods are more racially even. We argue that using a dissimiliarity index to measure the degree to which women are concentrated in departments mostly comprised of women and tracking this number across time will allow university administrators to see when, where, and if they are making progress in gender diversity and how much. Additionally, the creation of these indices can provide dependent variables for more complex, multivariate, explanatory models.

In 2016, 62 percent of the tenure-line faculty at the University of Tennessee were men (University of Tennessee Factbook, 2016). Hiring more tenure-line women would make the overall gender proportions look better, but adding more women to Child and Family Studies, which is already 93 percent women, will do little to improve diversity, while adding more women to Chemical and Biomolecular Engineering, which is 95 percent men, would improve diversity greatly.

In this paper, we demonstrate how to calculate a dissimilarity index (a measure of evenness), an isolation index, an exposure index, absolute concentration, and a location quotient (a measure of field proportionality) using gender data by department from the University of Tennessee. We focus on gender diversity, but the techniques employed here could be applied to other forms of diversity, such as race and disability status, given sufficient data access. The methods that we demonstrate are more appropriate for larger institutions like universities and should be used cautiously when applied to smaller institutions of higher education.

\section{DATA AND METHODS}

Our calculations require a count of an institution's total number of faculty men and women (separately) by Department. To demonstrate our methods, we obtained data from the University of Tennessee for 2016. We included only those faculty members with the title of professor (including assistant professors, associate professors, clinical professors, research professors, teaching professors, and so forth) excluding adjunct professors, visiting professors, and professors emeriti. We included deans and associate deans, since faculty in these positions frequently return to their home departments, and some participate in departmental life by teaching, conducting research, and so forth. We excluded lecturers and people for whom their status was unclear (e.g., internship coordinators). For faculty members holding joint appointments, we counted them twice (once in each department), since we could not determine a better means for allocating them. UTK Librarians were excluded from the analysis, because we were unable to ascertain who among them were tenure-line. Since the library faculty appears to be overwhelmingly comprised of women, the omission likely makes our results more conservative. Overall, researchers should follow their own logic and purpose in determining inclusion and exclusion criteria. We report ours only as a guide.

\section{Evenness: The Dissimilarity Index}

An index of dissimilarity (D) is calculated as:

$D=\frac{1}{2} \sum_{i=1}^{n}\left|\frac{m_{i}}{M_{T}}-\frac{w_{i}}{W_{T}}\right|$

where $\mathrm{n}=$ number of departments at a college or university,

$\mathrm{m}_{\mathrm{i}}=$ number of men in a department,

$\mathrm{M}_{\mathrm{T}}=$ total number of men in the college or university,

$\mathrm{W}_{\mathrm{i}}=$ number of women in a department, and

$\mathrm{W}_{\mathrm{T}}=$ total number of women in the college or university. 
In other words, for every department, researchers should take the number of men in a department and divide it by the number of men at the university. The same calculation should be done for women, and then the women's proportion is subtracted from the men's proportion in every department, ignoring whether the result is positive or negative. Once this is calculated for every department, the results are added together, and the sum is multiplied by .5. The resulting number is the index of dissimilarity.

\section{Exposure: Isolation and Interaction Indices}

Exposure can be conceptualized as the degree to which a woman is or is not likely to have colleagues in her department that are men. In other words, it is a measure of the degree to which women experience segregation, assuming that they interact with each faculty member in their department about the same amount. There are several measures of exposure. Two of the most common are the interaction index (also called the exposure index) and the isolation index. Mathematically, these two indices capture obverse conditions. Interaction measures the degree to which women are likely to have colleagues who are men. Isolation measures the degree to which women are likely to have colleagues who are also women. In the case of binary gender (i.e., when only two groups are being compared), the isolation and interaction indices sum to 1 , so it does not matter which is calculated, but there may be institutional reasons to select one over the other. If applying these measures to several groups, such as comparing several racial groups, a variant on this formula — called an entropy index — should be used.

An interaction index is measured as:

$B_{w m}=\sum_{i=1}^{n}\left(\frac{w_{i}}{W_{T}}\right)\left(\frac{m_{i}}{N_{i}}\right)$

where $\mathrm{n}=$ number of departments at a college or university,

$\mathrm{w}_{\mathrm{i}}=$ number of women in a department,

$\mathrm{m}_{\mathrm{i}}=$ number of men in a department,

$\mathrm{W}_{\mathrm{T}}=$ number of women at the university, and

$\mathrm{N}_{\mathrm{i}}=$ number of faculty in the department.

To calculate the interaction index (B), the proportion of the university's women represented by each department is calculated as the number of women in each department divided by the number of women at the university. Then the proportion of each department comprised of men is calculated by the number of men in each department divided by the total number of faculty. Those two proportions are then multiplied together for every department and those results are summed.

The isolation index is measured as:

$P *=\sum_{i=1}^{n}\left(\frac{w_{i}}{W_{T}}\right)\left(\frac{w_{i}}{N_{i}}\right)$

where $\mathrm{n}=$ number of departments at a college or university,

$\mathrm{w}_{\mathrm{i}}=$ number of women in a department,

$\mathrm{W}_{\mathrm{T}}=$ number of women at the university, and

$\mathrm{N}_{\mathrm{i}}=$ number of faculty in the department.

To calculate the isolation index $\left(\mathrm{P}^{*}\right)$, for each department, the number of women in the department are divided by the number of women at the university. Then the number of women in the department are divided by the number of faculty in the department. These two proportions are multiplied by each other, and then the department-level results are summed. The resultant number measures the degree to which women only encounter other women, assuming that women on tenure-line faculty only encounter those in their own department. The values of the isolation index range from 0 to 100, with 100 representing maximal isolation (i.e., women will encounter only other women). Note that the interaction and isolation 
indices are not symmetrical; they are minority-weighted. In order to understand how likely men are to encounter women colleagues or not, the indices would have to be recalculated.

\section{Concentration: Absolute Concentration}

In the study of residential segregation, concentration refers to the amount of physical space occupied by one group versus another. Specifically, Massey and Denton (1988) define concentration as the amount of physical space (typically square footage of living space) occupied by a minority group. With institutional data, a researcher could examine office and laboratory space allocated to faculty by gender. However, using one particular measure of concentration - absolute concentration - we can substitute for "space" a number of other useful resources that might vary by gender to measure vertical segregation as long as the substituted variable can be ordered. For example, "space" could be replaced by average student contact hours, average research budgets, average grant portfolio sizes, or average start-up funds.

To demonstrate the use of the absolute concentration to examine gender differences in resource allocation, we will measure "space" in terms of the aggregate claims of women on university politics through representation by their department heads. In other words, we define the amount of "political space" occupied by women, under the notion that each department head has the right to make claims for their faculty, and an individual woman in a large department may have less political influence than an individual woman in a small department. This, of course, is not strictly true and is problematic on many grounds, but we use it here only to demonstrate an application.

Concentration is described by Massey and Denton (1988) as "the total area inhabited by a group," compared with the "minimum and maximum possible areas that could be inhabited by that group," so we define the measure as:

$A C O=1-\frac{\sum_{i=1}^{n} w_{i} \frac{a_{i}}{N_{i}}-\sum_{i=1}^{n 1} a_{i}}{\sum_{i=n 2}^{n} a_{i}-\sum_{i=n 2}^{n} a_{i}}$

where first the data are sorted in ascending order based on $\mathrm{a}_{\mathrm{i}} / \mathrm{N}_{\mathrm{i}}$, with

$\mathrm{a}_{\mathrm{i}}=$ the "area" or size of a department,

$\mathrm{w}_{\mathrm{i}}=$ number of women in a department,

$\mathrm{N}_{\mathrm{i}}=$ number of faculty in the department,

$\mathrm{n} 1=$ the index of the department where the cumulative faculty total equals the total number of women in the university, counting from the smallest to largest, and

$\mathrm{n} 2=$ the index of the department where the cumulative faculty total equals the total number of women in the university, counting from the largest to smallest.

In our case, the area is the number 1 representing one department head, and the fraction $a_{i} / N_{i}$ is the size of an individual faculty member's claim on representation by their department head.

\section{Field Proportionality: The Location Quotient}

When examining faculty diversity, an important objective is to examine how departments do relative to their field. Given how few $\mathrm{PhDs}$ are given to women in computer science, for example, we cannot expect that many institutions' Computer Science Departments would have a large proportion of faculty members who are women. An examination of how departments fare relative to their field can be determined using a location quotient. Location quotients are sometimes used to study residential segregation, but they are more commonly used by economic geographers to examine the extent to which a city's industrial sector reflects the share of that industry in the state or country (Baer \& Brown, 2006). To apply this to the academy consider that, in 2013, about 13 percent of full professors in computer science were women (Corbett \& Hill, 2015); thus, a Computer Science Department that has no women at the ranks of full professor is not reflecting the field as a whole. Knowing the gender split in a field (information that is frequently available from professional organizations), those concerned with diversity 
in higher education can compare diversity in their own departments to national data to track progress and to see where Departments might be falling short.

Location quotients are calculated as:

$L Q_{i}=\left(\frac{w_{i}}{N_{i}}\right) /\left(\frac{E_{i}}{E}\right)$

where $\mathrm{w}_{\mathrm{i}}=$ number of women in a department,

$\mathrm{N}_{\mathrm{i}}=$ number of faculty in the department,

$E_{i}=$ number of women employed in field $i$, and

$\mathrm{E}=$ number of people employed in field $\mathrm{i}$.

In other words, the location quotient is calculated by dividing the proportion of a department that is women to the proportion of the field that is women. A location quotient of 1 means that a department's gender distribution matches the professorate nationally in the same field; a location quotient less than one indicates that the department's gender disparity is more unequal than the larger discipline. For example, if women hold only 1.5 percent of all tenure-line positions in a field in the United States and 16 percent of all tenure-line jobs in a department, then the location quotient is $(.16 / .015)=10.67$. In other words, the department is hiring women at about eleven times the field rate nationally. If the location quotient was .5, then the department's share of women is half of the average for the field. The Bureau of Labor Statistics indicates that location quotients between .8 and 1.2 are within a normal range for industries $\left(C_{2} E R, 2012\right)$, but we have no basis for asserting that this is a reasonable standard for universities to adopt.

\section{RESULTS}

\section{Evenness}

As previously noted, indices of dissimilarity yield scores between 0 and 1, with higher scores indicating greater evenness. An index of dissimilarity of 1 would mean that all women faculty are in allwomen departments, and all men faculty are in all-men departments. An index of 0 means that each department reflects the university's gender distribution as a whole. In other words, a score of 0 means that, since the university faculty is 36 percent women, each department is 36 percent women. Scores greater than 0 indicate a less equitable distribution of faculty across departments by gender. Our calculation of the index of dissimilarity for the University of Tennessee is .38 .

A score of .38 means that UT's departments are moderately segregated, with women somewhat likely to be in women-dominated departments and men somewhat likely to be in men-dominated departments. Technically, a score of .38 means that 38 percent of women would have to move to departments dominated by men (and vice versa) to achieve gender evenness. Since faculty are not substitutable - in other words, it would not make sense to relocate 38 percent of the Social Work faculty to the Physics Department and vice versa - the usefulness of this index is arguably best found in making comparisons over time or using these indices as dependent variables in multivariate models designed to examine differences across institutions.

A single point estimate of the index of dissimilarity is less valuable than a comparison of that estimate against prior years, to a benchmark goal, or against other institutions. To illustrate this, we compared a dissimilarity index calculated for UTK - where 36 percent of the faculty are women - to Texas A\&M University (TAMU) - where 31 percent of the faculty are women. (TAMU was chosen somewhat arbitrarily as an institution that made their data available.) Although the overall proportion of the faculty comprised of women is larger at UTK, the dissimilarity index for TAMU is .34, illustrating that the simple reporting of the global percent of women at the university can mask some segregation within departments.

Although universities tend to envision equity and diversity holistically, the calculation of the index of dissimilarity shows how equity and diversity are quite different concepts. Evenness is an indicator of 
diversity, but it is not an indicator of equity. Since the University of Tennessee's tenure line faculty are split about 60-40, men to women, the index of dissimilarity measures the degree to which departments match this split. UTK's Department of Psychology — which is almost equally divided with 1.1 men for every woman - is equitable but not "even," because its nearly 50-50 gender split does not reflect UTK's 60-40 gender split. The UTK Departments that are most "even" are Classics; Kinesiology, Recreation, and Sports Studies; Modern Foreign Languages and Literature; Music; and Sociology. Each has about 1.67 men for every woman, as does the university, overall. The least gender-diverse departments at UTK are Mechanical, Aerospace, and Biomedical Engineering (16.3 men for every woman) and Nursing (13.7 women for every man).

This begs the question of whether evenness is important. Would it not be better for more departments to be like Psychology, with about as many men as women? While not disputing this, certain types of institutions would tend to skew toward more men faculty since they tend to offer training in maledominate fields like engineering and agriculture. In these cases, a measure of evenness has value. We also argue that - regardless of a university's orientation - an institution of higher education with an index of dissimilarity close to 1 (or hyper-segregated) should do more to achieve diversity across departments. Still, we would posit that it is more troubling for individual departments to lack diversity than equity, given gender differences in fields as a whole.

\section{Exposure}

Exposure is important because organizational research suggests that mixed gender work teams are more innovative (Ely \& Thomas, 2001; Dezsö \& Ross, 2012; Rock, Grant, \& Grey, 2016). Since universities are often in the business of creating new knowledge, gender diversity at the department level can facilitate this. Having a mixed gender department does not guarantee that men and women will collaborate, but it is arguably harder to have mixed gender collaborations in departments that are dominated by a single gender.

For women on faculty at UTK, their interaction index is .50. This means that a woman on tenure-line faculty at UTK would have about a 50 percent chance of encountering a male colleague, assuming that she has the same chance of encountering all of her colleagues. Unlike the dissimilarity index, interaction depends on the size of the two groups being compared, so the top end of the interaction index is bound by the proportion of the second group. In other words, since men make up 64 percent of UTK's faculty, the highest possible interaction index for women would be .64. Obtaining a maximal value requires that the index of dissimilarity equal zero.

For women faculty at UTK, the isolation index is also .50. This means that there is a 50 percent probability that a professor who is a woman will only encounter other women assuming that she has an equal chance of encountering every other professor in her department. Given the research that demonstrates the value of mixed-gender governance and interactions (Campbell \& Mínguez-Vera, 2008), especially in complex environments that engage in risk (Francoeur, Labelle, \& Sinclair-Desgagné, 2008), such as research universities, regularly encountering colleagues of another gender matters. College and university officials should track interaction and isolation indices across time to ensure that they are making progress in ways that benefit their institutions.

\section{Concentration}

At the University of Tennessee, women faculty could almost entirely fill the 12 largest department or the 36 smallest departments, representing bounds on the amount of space that could be occupied by women. If smaller departments give more voice to women, and women tend to be in smaller departments, then a larger ACO would mean better outcomes (in theory). For UTK, the absolute concentration is .501, indicating that women are not systematically located in large or small departments. For example, among the 12 largest departments, there are some departments, like Mechanical Engineering and Mathematics with many more men, and other departments, like Small Animal Clinical Sciences and Nursing with many more women. 
The concentration measure employed here is really a measure of the distribution of women across the distribution of departments according to some size or density measure. For the University of Tennessee, this measure does not seem very helpful and the application of the measure this way entails many problematic assumptions. However, this measure is likely quite helpful when examining other resource allocations where data are available. Again, we offer this application here simply as one example of how this measure could be used.

\section{Field Proportionality}

We calculated the location quotient for the several engineering departments at UTK compared against 2014-2015 data from the American Society of Engineering Education (Yoder 2016) limiting our comparisons to just those holding tenure-line positions. We readily admit a mismatch between the year that our institutional data were collected (2016) and the year the ASEE data were collected. However, given that progress in diversity in education is incrementally slow (Shaw \& Stanton, 2012), we do not expect that the fields of engineering have changed much over two years. Until newer data are released, it will be impossible to determine how far off our calculations are, but it is likely that our results are conservative.

\section{FIGURE 1 \\ FIELD PROPORTIONALITY FOR ENGINEERING DEPARTMENTS}

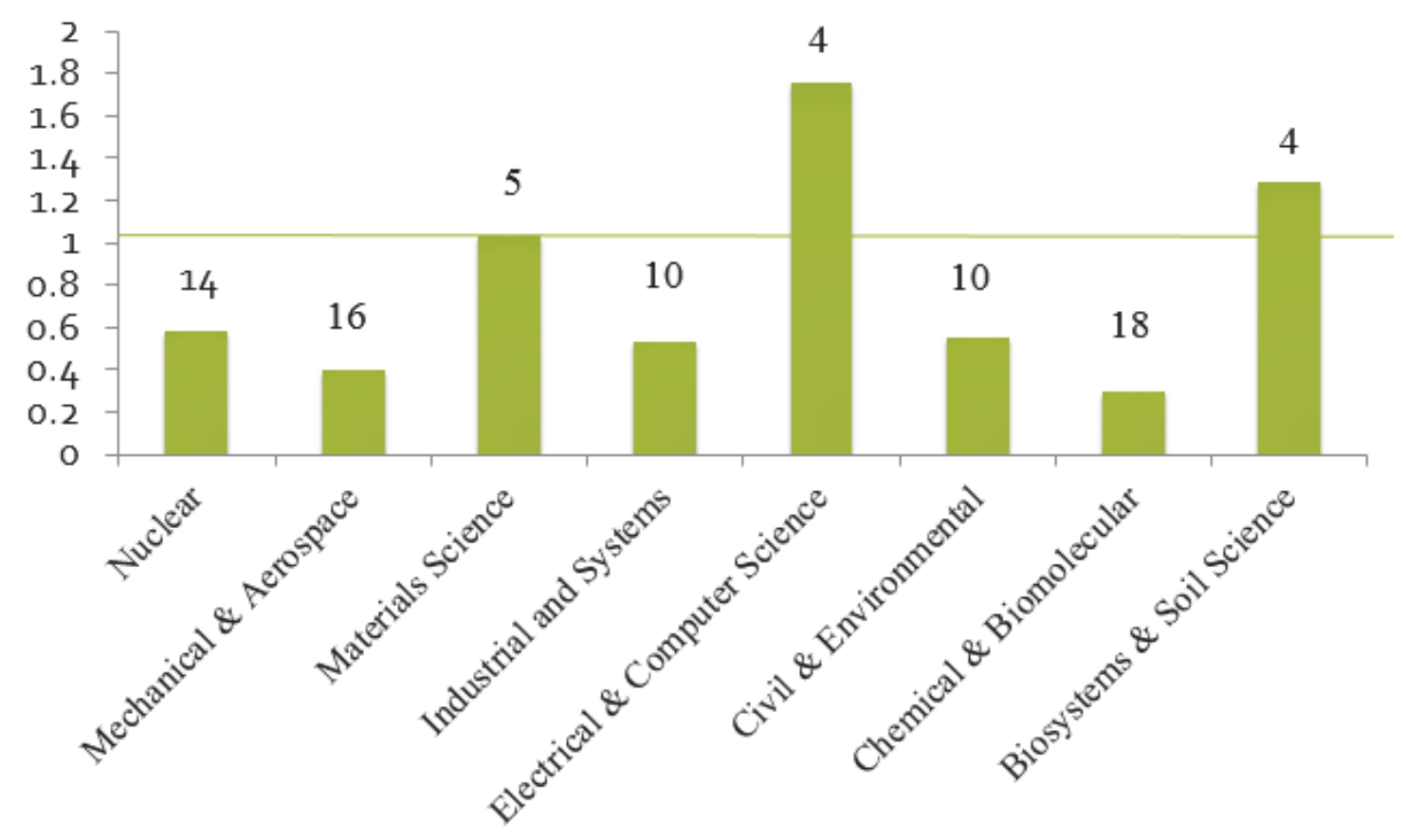

NOTE: Numbers above the bars represent department sex ratios (number of tenture-line men for every tenure-line woman). The horizontal line at 1 represents the gender composition of the labor market, which is different for each field.

As shown in Figure 1, at UTK, the location quotient for Industrial and Systems Engineering is .53, Chemical and Biomolecular Engineering is .30, Civil and Environmental Engineering is .55, Electrical Engineering and Computer Science is 1.76, Materials Science and Engineering is 1.03, and Nuclear Engineering is .58. The numbers above the bars represent the number of tenure-line men for every woman 
in that Department, and the distance of the bar over or under the line represents how many more or less women the Departments hired, respectively, compared to their field as a whole.

Our results indicate that the gender distribution in Materials Science and Engineering-where men outnumber women 5 to 1 -is reflective of the gender distribution of the field as a whole. Electrical Engineering and Computer Science is better than many other universities in attracting women to tenureline jobs. By contrast, we would argue that our administration should take a closer look at gender conditions in the Departments of Industrial and Systems Engineering, Chemical and Biomolecular Engineering, Civil and Environmental Engineering, and Nuclear Engineering. These departments are attracting and/or retaining women on the tenure-line at a rate lower than what would be expected given the supply of women in these fields of engineering.

Although the calculation of a location quotient is mathematically simple, the ASEE data illustrate that not all calculations are conceptually straightforward. For example, at UTK, three of the tenure-line faculty in Mechanical, Aerospace, and Biomedical Engineering are women, and 49 are men. Thus, $\left(\mathrm{e}_{\mathrm{i}} / \mathrm{e}\right)$ is .06, indicating that women are 6 percent of the faculty in that department. However, ASEE reports mechanical, aerospace, and biomedical engineering separately (13.5, 9.1 and 22 percent women, respectively) whereas UTK combines faculty with this expertise into a single department. We added the three ASEE percentages as a total and divided by 300 to get .15. Thus, the location quotient for the department at UTK as a ratio to the field is .4, indicating that the Department has far fewer women than are in these fields in tenure-line positions nationally. However, since the Department is comprised of three fields, a field proportionality quotient of .4 is more alarming if most of the Department is comprised of biomedical engineers and less bad-but still not good-if most of the faculty members in the Department are aerospace engineers.

It is also worth noting that the location quotient may hide gender divides within departments, depending on how departments are structured. For example, the location quotient for Biosystems Engineering and Soil Science is 1.29, but what looks on the surface as a good situation for women (i.e., they are being hired at 1.29 times the national rate) may mask the fact that the biosystems engineers in the Department could be all men, while the plant pathologists, horticulturalists, and botanists could be all women. To the extent that differential prestige and salaries are allocated across these specializations, vertical gender segregation may still be an issue.

Although the calculation of the location quotient is quite simple, we speculate that this calculation is the most time-consuming calculation with respect to data acquisition. Finding national data is difficult. Additionally, some associations make their data available only to members. Presumably there are fields where no gender data are collected; we only looked at engineering. The National Science Foundation captures gender information from the STEM fields, but they report these data in broad categories which make them hard to apply at the department level.

Additionally, we do not know to what extent we may be making poor comparisons. For example, ASEE reports gender data on Biological and Agricultural Engineering, which we compared to UTK's Department of Biosystems Engineering and Soil Science. We are unsure whether that is a straightforward comparison or not, and conversations with women who are faculty members in this Department suggest that it is not. Additionally, ASEE reports data on Electrical/Computer Engineering (of which women comprise 12.4 percent of the field) as well as Computer Science within engineering (of which women comprise 16.9 percent of the field). It was unclear to us which denominator to use in the UTK calculation. Still, these numbers give some indication of the Departments which need the most improvement, and field proportionality numbers can be used to guide administrators in making decisions about which departments might best benefit from the opportunity to make strategic hires of women.

\section{CONCLUSIONS}

Gender equity in higher education means more than simply filling half of all tenure-line positions with women. In order to derive the benefits of diversity, women and men have to work in the same spaces, and some fields need to attract more women. As universities attempt to increase diversity by 
creating programs to attract more women to STEM and other traditionally male-dominated fields (Shaw \& Stanton, 2012; Xu, 2008), a larger set of tools is needed to allow administrators to examine the gains they may be making in gender diversity in more than a uni-dimensional way.

We offer some relatively simple tools for measuring progress toward vertical gender integration. In this paper, we draw from the literature on residential segregation to suggest adding four dimensions to the understanding of faculty gender segregation-evenness, isolation, concentration, and field proportionality. In the cases of evenness and isolation, we suggest that point estimates for a single year are less valuable than using those estimates to compare across time and to peer institutions. We also argue that measures of concentration allow considerable flexibility in defining "space" in order to examine many ways in which resources may be differentially allocated by gender. The location quotient helps to compare an individual department to its discipline. Location quotients can help administrators better allocate diversity resources, because they can be used to determine which departments may need the most attention and develop new strategies for early recruitment, create a more inclusive work environment, develop a retention plan, improve mentoring, or take other steps to improve diversity. These methods are not perfect, but they improve upon the basic percentages that are often used.

The techniques we explicate here do not provide evidence, in and of themselves, for vertical gender segregation, but they provide a warning that a problem may exist. For example, the evidence of hypersegregation (i.e., a high dissimilarity index) does not indicate in and of itself that women faculty members are clustering in lower paying or less prestigious departments, but prior research suggests that the chances are good (Misra, Kennelly, \& Karides, 1999; Probert, 2005; Weisshaar, 2017). So segregation indices can indicate a need for further exploration. Certainly, vertical gender segregation in higher education has been studied extensively over many years (c.f. Berggren, 2008; Charles \& Bradley, 2002; 2009) using in-depth and complex techniques, but administrators need information that is more immediate and accessible, and we provide a means of obtaining that information.

In this paper, we examined gender, but the techniques we used were initially developed to study racial segregation. Thus, all calculations presented here could be applied to other dimensions of diversity such as race, LGBTQ status, non-binary gender, or disability status. With access to other institutions' data, or by using big data techniques such as web scraping and machine learning, interested parties could also compare across similar institutions.

Obviously, using residential segregation measures to study inequality in the professorate has its limitations. Our primary purpose is to show how university administrators can better evaluate diversity using data that are readily available to them. Care is needed to not read more into the indices than the data provide. Demographers have long discussed the limitations of various measures of residential segregation, including the measures used here (see, for example, James \& Taeuber, 1985; Fossett, 2011). Researchers should also anticipate the need to create many decision rules about which cases are included, since every university is different. We included administrators, excluded adjuncts, part-time faculty, and librarians, and we did not adjust for rank. All of these decisions likely impacted our results. Those comparing across institutions should also be careful to create models that adjust for structural differences across institutions. Still, since the alternative to these measures at most institutions is percentages by sex, we argue that better measures than those can be generated without a great deal of work or the need for complex interpretation. 


\section{REFERENCES}

Baer, C., \& Brown, T. (2006, March). Location quotients: A tool for comparing regional industry compositions. InContext: Indiana's Workforce and Economy. Retrieved from http://www.incontext.indiana.edu.

Bayer, A., \& Rouse, C. E. (2016). Diversity in the economics profession: A new attack on an old problem. Journal of Economic Perspectives, 30(4), 221-242. doi:10.1257/jep.30.4.221.

Berggren, C. (2008). Horizontal and vertical differentiation within higher education: Gender and class perspectives. Higher Education Quarterly, 62(1-2), 20-39. doi:10.1111/j.1468-2773-200800381.x.

Bystydzienski, J., Thomas, N., Howe, S., \& Desai, A. (2017). The leadership role of college deans and department chairs in academic culture change. Studies in Higher Education, 42(12), 2301-2315. doi:10.1080/03075079.2016.1152464.

Campbell, K., \& Mínguez-Vera, A. (2008). Gender diversity in the boardroom and firm financial performance. Journal of Business Ethics, 83(3), 435-451. doi:10.1007/s10551-007-9630-y.

Charles, M., \& Bradley, K. (2002). Equal but separate? A cross-national study of sex segregation in higher education. American Sociological Review, 67(4), 573-599. doi:10.2307/3088946.

Charles, M., \& Grusky, D. B. (2004). Occupational ghettos: The worldwide segregation of women and men. Stanford, CA: Stanford University Press.

Corbett, C., \& Hill, C. (2015). Solving the equation: The variable for women's success in engineering and computing. Washington, DC: American Association of University Women.

Crowder, K., \& Krysan, M. (2016). Moving beyond the big three: A call for new approaches to studyingracial residential segregation. City \& Community, 15(1), 18-22. doi:10.1111/cico.12148.

$\mathrm{C}_{2}$ ER [Webinar]. (2012, September 14). Calculating location quotients. LMI Training Institute. Retrieved from https://www.c2er.org.

Dezsö, C. L., \& Ross, D. G. (2012). Does female resspresentation in top management improve firm performance? A panel data investigation. Strategic Management Journal, 33(9), 1072-1089. doi:10.1002/smj.1955.

Ely, R. J., \& Thomas, D. A. (2001). Cultural diversity at work: The modertating effects of work group perspectives on diversity. Administrative Science Quarterly, 46(2), 229-273. doi: $10.2307 / 2667087$.

Francoeur, C., Labelle, R., \& Sinclair-Desgagné, B. (2008). Gender diversity in corporate governance and top management. Journal of Business Ethics, 81(1), 83-95. doi:10.1007/s10551-007-9482-5.

Hale, G., \& Regev, T. (2014). Gender ratios at top PhD programs in economics. Economics of Education Review, 41(3), 55-70. Doi:10.1016/j.econedurev.2014.03.007.

Iceland, J., Weinberg, D. H., \& Steinmetz, E. (2002). Racial and ethnic residential segregation in the United States: 1980-2000. US Census Bureau, Series CENSR-3, Washington, DC: US Government Printing Office.

Indulging our gendered selves? Sex segregation by field of study in 44 countries. (2009). American Journal of Sociology, 114(4), 924-976.

Jacobs, J. A. (1998, December). Measuring time at work: Are self-reports accurate? Monthly Labor Review. Retrieved from https://www.bls.gov.

Li, D., \& Koedel, C. (2017). Representation and salary gaps by race-ethnicity and gender at selective public universities. Educational Researcher, 46(7), 343-354. doi:10.3102/0013189X17726535.

Massey, D. S. (1985). Ethnic residential segregation: A theoretical synthesis and empirical review. Sociology and Social Research, 69(3), 315-350.

Massey, D. S. (1990). American apartheid: Segregation and the making of the underclass. American Journal of Sociology, 96(2), 329-357.

Massey, D. S., \& Denton, N. A. (1988). The dimensions of residential segregation. Social Forces, 67(2), 281-315. doi:10.2307/2579183.

38 Journal of Higher Education Theory and Practice Vol. 19(6) 2019 
Misra, J., Kennelly, I., \& Karides, M. (1999). Employment chances in the academic job market in sociology: Do race and gender matter? Sociological Perspectives, 42(2), 215-47. doi:10.2307/1389628.

Moss-Racusin, C. A., Dovidio, J. F., Brescoll, V. L., Graham, M. J., \& Handelsman, J. (2012). Science faculty's subtle gender biases favor male students. Proceedings of the National Academy of Sciences, 109(41), 16474-16479. doi:10.1073/pnas.1211286109.

Probert, B. (2005). "I just couldn't fit it in": Gender and unequal outcomes in academic careers. Gender, Work \& Organization, 12(1), 50-72. doi:10.1111/j.1468-0432.2005.00262.x.

Reskin, B., \& Roos, P.A. (1990). Job queues, gender queues: Explaining women's inroads into male occupations. Philadelphia: Temple University Press.

Rock, D., Grant, H., \& Grey, J. (2016, September 22). Diverse teams feel less comfortable - and that's why they perform better. Harvard Business Review. Retreived from https://hbr.org.

Shaw, A. K., \& Stanton, D. E. (2012). Leaks in the pipeline: Separating demographic inertia from ongoing gender differences in academia. Proceedings of the Royal Society-B: Biological Sciences, 279, 3736-3741. doi:10.1098/rspb.2012.0822.

University of Tenneessee Office of Institutional Research and Assessment. (2016). University of Tennessee, Knoxville Fact Book. Retrieved from https://oira.utk.edu/factbook/archive.

Weisshaar, K. (2017). Publish and perish? An assessment of gender gaps in promotion to tenure in academia. Social Forces, 96(2), 529-560. doi:10.1093/sf/sox052.

Xu, Y. J. (2008). Gender disparity in STEM disciplines: A study of faculty attrition and turnover intentions. Research in Higher Education, 59, 607-624. doi:1.1007/s1162-008-9097-4.

Yoder, B. L. [Report]. (2016). Engineering by the Numbers. American Society for Engineering Education. Retrieved May 18, 2018, from https://www.asee.org. 